\title{
Islamismo, yihadismo y extrema izquierda en América Latina. ¿Hacia una teoría y una práctica islamizadas de la revolución?
}

\section{Islamism, Jihadism and Extreme Left in Latin America. Is there an Islamized Theory and Practice of Revolution?}

Pedro Rivas Nieto ${ }^{2}$

Universidad Loyola Andalucía (España)

ORCID: https://orcid.org/0000-0002-2829-7294

\author{
Pablo Rey García ${ }^{3}$ \\ Universidad Pontificia de Salamanca (España) \\ ORCID: https://orcid.org/0000-0001-9962-7003
}

Recibido: 13-12-2019

Aceptado: 03-04-2020

\section{Resumen}

Este artículo estudia la hipotética penetración del islamismo -vertiente degradada del Islam-en algunos sectores de la extrema izquierda en Latinoamérica y reflexiona sobre su habilidad para desarrollar tanto una teoría como una práctica

\footnotetext{
${ }^{1}$ Este artículo se liga con el proyecto de investigación titulado Protección de las minorías frente a los discursos del odio, cuya referencia es DER2015-66189-P y fue financiado por el Ministerio de Economía y Competitividad del Gobierno de España.

2 (privas@uloyola.es) Profesor Titular y Vicedecano de la Facultad de Ciencias Jurídicas y Políticas de la Universidad Loyola. Su campo de trabajo es la violencia política. Entre sus publicaciones están Terrorismo y antiterrorismo en el mundo contemporáneo. Bogotá (Colombia), Penguin Random House Mondadori, Sello Debate, 2012; Doctrina de Seguridad Nacional y regímenes militares de Iberoamérica. Alicante, Club Universitario, 2009; y, con Pablo Rey, Orden internacional y conflictos, Madrid, Editorial Biblioteca Nueva, 2007.

3 (preyga@upsa.es) Profesor de Relaciones Internacionales en la Universidad Pontificia de Salamanca. Sus líneas de investigación abarcan el conflicto, la fotografía y la propaganda de guerra. Sus últimas publicaciones son Rey-García, P.; Rivas-Nieto, P.; McGowan, N. (2020) "War memorials, between propaganda and history: Mleeta Landmark and Hezbollah". Cultural Trends. pp. 1-19. https://doi.org/10.1080/09548963.2020.1815175; "Los conflictos armados", en Escudero Vidal et al. (2020) Visión compartida sobre los derechos del niño, pp. 291-300. Lima (Perú): Fondo editorial de la Universidad Marcelino Champagnat y Rey-García, P.; Rivas-Nieto, P.: "Refugees and Photography: aesthetic, art and awareness of pain". En Puell de la Villa et al. (2018) War and Population Displacement. pp. 176-193. Sussex Academic Press.
} 
islamizadas de la revolución. El objetivo de esto es indagar en un aspecto inusual de la seguridad, el factor ideológico, habitualmente soslayado por preferirse los elementos estratégicos y tácticos. Para ello primero se investigan someramente algunos cambios del terrorismo ligados al islamismo en Latinoamérica. Después se analiza la doctrina mediante la que el islamismo puede conectar con la extrema izquierda mediante los conceptos de revolución, guerra revolucionaria, guerra asimétrica y yihad. Finalmente están las conclusiones del artículo.

Palabras-clave: islamismo, yihad, terrorismo, guerra, revolución.

\section{Abstract}

This article investigates how Islamism - not Islam- is penetrating into ideological extremism in Latin America. Its goal is to have an impact on a key aspect of security for Latin America that is often avoided. First, regional terrorist trends are shown. After that, links to extreme left are studied, next to the concepts of revolution, jihad and revolutionary and asymmetric war. Finally, conclusions of the article and suggestions for future research are shown.

Key-words: Islamism, Jihad, Terrorism, War, Revolution.

\section{Introducción}

A finales del siglo XX parecía que la recobrada seguridad colectiva del Nuevo Orden Mundial reducía la violencia. Sin embargo, los hechos lo negaron. La guerra y el terrorismo rompieron los moldes clásicos y mostraron un nuevo rostro: minorías étnicas alzadas en armas, grupos fanatizados por una fe febril o conflictos cuyo interés principal era el control del territorio para dominar el narcotráfico u otras actividades ilícitas. En las tierras situadas al otro lado del limes, de la frontera entre el mundo civilizado y la barbarie, la "guerra harapienta", tal y como la entrevió Thompson de forma premonitoria (en Ignatieff 1999: 122), se había convertido en un aspecto más de la vida cotidiana. Los nuevos hacedores del terror desgarraban los restos de algunas naciones -antes, Yugoslavia; en tiempos recentísimos, Irak y Siria- y degradaban los valores que Occidente intentaba extender, a veces de buena fe, por el mundo.

Algo de esto le pasaba también a Latinoamérica. En el continente cuyos Estados se jactaban de haberse hecho la guerra unos a otros, a diferencia de los europeos, en escasas ocasiones (Centeno 2014), no se frenaba eficazmente la violencia interna e incluso parecía aumentar, pues arraigaba tanto en Estados endebles que padecieron conflictos prolongados -los centroamericanoscomo en otros tradicionalmente sólidos -México, Argentina, Brasil-, o de difícil catalogación -Colombia-. No en vano desde el fin de la Guerra Fría 
las discusiones sobre seguridad en Latinoamérica se habían centrado en su multidimensionalidad, pues los tres grandes problemas que afectaban a la seguridad hemisférica eran la crisis de la gobernación democrática, los conflictos armados -internos esencialmente- y la extensa criminalidad creada por la delincuencia transnacional organizada y por la violencia social (Chanona 2011: 107-135).

Esta era, grosso modo, a punto de cerrarse el segundo decenio del siglo XXI, la situación de América Latina (Rainier 2017), que no era tan ajena a la del resto del mundo. Y ésta es la situación de partida de este estudio. Dicho de otra forma: si las formas de la violencia cambian, también lo hace una de las más conocidas de nuestro tiempo, el terrorismo, por mucho que sigan siendo válidos los estudios considerados canónicos (Reinares 2015 y 1998; Avilés 2012; Rapoport 2011; Hoffman 2006; Clutterbuck 2004; Juergensmeyer 2003; Wiewiorka 1988; Laqueur 1987; Wilkinson 1986; Wardlaw 1986; Schmidt 1984). Y como sería imposible revisar en un solo artículo de investigación todas las modificaciones del terrorismo -organizativas, tácticas...- para establecer una teoría general, nos centraremos en estudiar solo uno de los aspectos en los que se perciben los cambios. Dado que en el terrorismo es crucial lo ideológico, ese es el motivo de que en este trabajo se quieran estudiar las conexiones entre ideologías aparentemente lejanas.

Estos puntos llevan a formular una cuestión fundamental para este artículo: si el islamismo -vertiente degradada del Islam- se extiende, y si el terrorismo adquiere nuevo rostro en Latinoamérica -algo probable al revisar indicios y sucesos en otras zonas del mundo-, podría deducirse que a los extremismos y al terrorismo de Latinoamérica les ha llegado, y lo sigue haciendo, el influjo del islamismo. De esto surge la hipótesis principal: quizá el islamismo puede encajar en algunos sectores de la extrema izquierda porque la naturaleza ideológica de ambas doctrinas lo permite, e incluso lo facilita. Esta afirmación -de apariencia categórica- no se hace a la ligera, pues ya ha ocurrido en la extrema derecha, como se señalará luego en este trabajo. Por ello, indicios y experiencias acumuladas sugieren una posibilidad semejante en la extrema izquierda, aunque a priori pudiera sonar raro por las distancias ideológicas que parece tener con el islamismo, y por la lejanía física, cultural e histórica de Latinoamérica con el mundo arabomusulmán. $\mathrm{Si}$, además, ha habido y hay conexiones crecientes entre grupos clásicamente latinoamericanos y otros islamistas, cabría plantearse lo siguiente, a modo de hipótesis secundaria: la conjunción de ambas acaso permitiría elaborar una teoría y una práctica islamizadas de la revolución. No es desatinado pensarlo. Al fin y al cabo, en política no debe tenerse en cuenta lo imposible, pero sí lo improbable. 
Para sacar adelante este análisis se ha recurrido a fuentes documentales de disciplinas diversas, fuentes orales, trabajo exegético y de campo. Se han examinado documentos ligados con las ideologías políticas y el terrorismo en centros de investigación de países de Oriente Próximo (American University, Beirut; Hebrew University, Jerusalén; Meir Amit Intelligence and Terrorism Center, Tel Aviv) y de América Latina (Universidad Católica, Chile; Universidad de Buenos Aires, Argentina; Universidad Pontificia Bolivariana, Colombia) durante varias estancias de investigación llevadas a cabo en distintos períodos. El análisis de documentos se ha complementado con conversaciones con miembros de grupos extremistas en varios de esos países (Líbano, Israel, Colombia) y en territorios que no tienen ese estatus (Cisjordania) cuyos contenidos se han utilizado, tras depurarlos. Esas reuniones se contrastaron con entrevistas a agentes de inteligencia ${ }^{4}$, cuyos testimonios se diseccionaron cuidadosamente para favorecer las reflexiones que dan forma a este trabajo. La técnica aplicada a las fuentes humanas fue la entrevista no estructurada de élites (Manheim y Rich, 1986: 182), basada en la clásica focused interview de Merton, Fiske y Kendall, en la que los investigadores seleccionan a expertos a quienes se interroga buscando categorías específicas de estudio. A diferencia de la encuesta de muestra representativa, no se entrevista aleatoriamente; y a diferencia de la habitual entrevista estructurada, se busca que el encuestado sea quien organice el relato de los hechos examinados. El fin es una flexibilidad mayor, que permite tener en cuenta diferentes interpretaciones de los hechos.

El artículo se organiza de la siguiente manera: tras esta introducción se mostrará qué ocurre con el terrorismo en la región para esbozar sus tendencias. Como el objeto no es examinar su naturaleza ni delimitar sus fronteras, ese apartado será un estudio somero, preparatorio para lo que vendrá después: el análisis del extremismo izquierdista, para averiguar si en él -a priori ajeno naturalmente a esta doctrina-puede penetrar el islamismo $\mathrm{y}$, de hacerlo, confirmar ciertos efectos visibles en el comportamiento del terrorismo en la región. Por eso, en tercer lugar, se estudiarán los razonamientos doctrinales por los que el islamismo conecta con la extrema izquierda: el concepto de revolución, los vínculos que se han construido entre ella y el yihad ${ }^{5}$, y los conceptos de guerra revolucionaria y guerra asimétrica. Finalmente están las conclusiones del artículo, que contienen reflexiones y sugerencias para investigaciones futuras.

\footnotetext{
${ }^{4}$ Cuando en el texto se haga referencia a una "entrevista con agentes de inteligencia" se abreviará así: EAI, seguido del año en que tuvo lugar. Por motivos obvios no se dirán nombres, nacionalidades o lugares en los que se obtuvo la información.

5 A pesar de que en español suela decirse la yihad, probablemente por analogía con el vocablo guerra, en este artículo se emplea el sustantivo en masculino por ser éste su género en árabe.
}

Araucaria. Revista Iberoamericana de Filosofia, Politica, Humanidades y Relaciones Internacionales, año $23, \mathrm{n}^{\circ} 46$. Primer cuatrimestre de 2021. Pp. 215-237. ISSN 1575-6823 e-ISSN 2340-2199 https://dx.doi.org/10.12795/araucaria.2021.i46.11 


\section{Modificaciones generales del terrorismo en América Latina}

\subsection{Esbozo de la tendencia}

Es importante tener en cuenta, de forma somera ${ }^{6}$, cómo han cambiado algunas pautas en la actuación de las organizaciones terroristas para entender su relevancia, a saber: los grupos son más poderosos, tienen más miembros, menos límites morales, sus actos son más letales, mezclan ideologías a su conveniencia en un mundo globalizado, se vinculan con actores nacionales o internacionales dedicados al delito común y, cada vez con más frecuencia, lo religioso es un factor clave que refuerza sus capacidades de control de las mentes e incluso de los territorios (Upal 2015; Post, McGuinnis, Mody 2014; Jones y Johnston 2013; Mogahdam 2013; Weinberg y Eubank 2010). Sería útil señalar sucintamente los patrones y alianzas de esta violencia en América Latina para estudiar después la penetración de ideologías aparentemente ajenas a lo habitual en el continente.

Desde hace años hay constancia de que algunos grupos terroristas originarios de las Américas tienen relaciones con los de otras zonas del mundo, especialmente de Europa y, excepcionalmente -aunque de forma creciente-, de Oriente (Kahati 2019; EAI 2018; Rainier 2017; Caro 2011, 2010, 2009; Schoen y Rowan 2009; Merlos 2009; Karmon 2009, 2006; Nasr 2006; Byman 2001). El caso más claro fue siempre el de las FARC, cuyas relaciones con grupos europeos -ETA, IRA- son bien conocidas (Domínguez, 2010) y además se sospecha (Kahati 2019; EAI 2018; Rainier 2017) que mantenía lazos con grupos de Oriente Próximo. Estas modificaciones hablan por sí solas de cómo las amenazas han cambiado, pues además han añadido al viejo guerrillerismo y al terrorismo valores de bandas criminales. Este proceso de ligazón del crimen y del terrorismo (Wang 2010: 11-20), es en buena medida extrapolable al resto del continente en estos tiempos.

Estas cuestiones -dado que no es posible explicar de forma pormenorizada casos concretos y ceñirse, a la vez, a los límites de un artículo académicopueden observarse en hechos de apariencia anecdótica que, de facto, dan la medida de las cosas tanto al especialista como al profano. Por ejemplo, que la región andina -en donde han estado las FARC y están activos el ELN, o Sendero Luminoso, por citar dos casos- se da un aire al Sahel. ¿Por qué?

\footnotetext{
${ }^{6}$ No es obligado en este artículo ceñirse a escuelas o a autores renombrados para definir el terrorismo, ni emplear una sola definición científica, porque en los estudios sobre terrorismo se reconoce desde hace tiempo que hay más de cien definiciones académicas válidas (Schmidt, 1984). Por ello se empleará una que contenga y delimite los principios esenciales y las constantes de un fenómeno que cambia con gran rapidez: el terrorismo es violencia premeditada, con motivaciones y fines políticos, ejecutada por agentes clandestinos contra objetivos no combatientes, que quiere enviar mensajes con su violencia para modificar las conductas, más que matar o destruir.
} 
Porque en ambas hay terrorismo, el narcotráfico intercontinental las relaciona ${ }^{7}$, hay movilidad creciente de población entre ellas, el Estado es débil y la historia de sus últimos cuarenta años se parece (Teirilä 2014: 21-22). Esto indica que hay relaciones crecientes entre las áreas del mundo en las que se "forjan" los islamistas -no necesariamente yihadistas, aunque la radicalización en una idea deformada del Islam sea el paso previo para la movilización y el encuadramiento- y el continente americano.

También en el continente está activo Hizbolá, fortalecido en la Triple Frontera (Rudner 2010: 705-706) al aprovecharse de la diáspora libanesa para obtener fondos por medios ilícitos - con una estructura financiera familiar y clánica similar a la de sus grupos en África- más que para cometer atentados (Rainier 2017), y desde hace un decenio está también en Isla Margarita, Panamá, Sao Paulo e Iquique. Es apoderado de Irán en la región además de apoyo para sus actividades ocultas (Karmon 2009: 18-31), lo cual no impide que desde 2005 Irán haya fortalecido sus lazos con Venezuela, Bolivia, Ecuador, Nicaragua, Brasil, Paraguay y Argentina. Al mismo tiempo tiene su propia agenda ligada a sus objetivos estratégicos de alcance mundial (Badran 2010: 9) e infraestructuras que dan apoyo logístico y operativo a terroristas cualificados que puedan atentar y, tras ello, irse del país. Cuando desaparecen, queda la red. Estas infraestructuras son sólidas en Europa, África Oriental y América del Sur (Bar 2007: 477-478). Ammar Al Mussawi (2016), jefe de relaciones exteriores de Hizbolá, informó a los autores de este escrito en Beirut que, desde hace algún tiempo, Hizbolá no lleva a cabo transacciones financieras en Europa, ni compraventa de armas, pero no negó explícitamente que se hicieran en América.

Es precisamente el narcotráfico - elemento habitualmente facilitador del terrorismo- el que ayuda a la transmisión de ideas y de tácticas entre grupos que trabajan en diferentes lugares. Por ejemplo, en África Occidental, en Colombia o en Perú. Sendero Luminoso, que vuelve a estar activo, se relaciona a la vez con el cartel de Sinaloa y con grupos de Oriente, como hizo Al Qaeda con la Camorra italiana: había beneficios mutuos pese a sus diferentes objetivos (Chepesiuk 2007).

\subsection{El narcotráfico como factor clave}

Precisamente porque la relación del terrorismo y del crimen organizado no es ninguna novedad y porque suele soslayarse este elemento en los grupos terroristas religiosos, conviene prestarle atención. Es una amenaza a la seguridad internacional (Vargas 2011: 21-39; McMullin 2009: 75-102)-que

7 Sustancias ilícitas producidas en el Cono Sur cruzan el Atlántico y, tras llegar al Sahel, se distribuyen desde ahí a Europa.

Araucaria. Revista Iberoamericana de Filosofia, Politica, Humanidades y Relaciones Internacionales, año $23, \mathrm{n}^{\circ} 46$. Primer cuatrimestre de 2021. Pp. 215-237. ISSN 1575-6823 e-ISSN 2340-2199 https://dx.doi.org/10.12795/araucaria.2021.i46.11 
puede darse especialmente en América Latina- y es frecuente porque hay muchas similitudes entre ambos: lo que los diferencia es, grosso modo, la motivación de sus actos (Shelley y Picarelli 2002: 305-318). Ya desde antes del 11-S la relación entre narcotráfico, tráfico de armas y terrorismo era habitual, pero estas actividades cada vez convergen con más frecuencia.

Los principales factores explicativos de las conexiones terrorista-criminales se concentran en una idea: sin alianza habría una debilidad estratégica difícil de superar en solitario por el grupo terrorista, o por la banda de delincuentes. Al unirse estas dos formas de delito, se buscan habilidades inexistentes entre los miembros de una organización, se favorece la oportunidad de crear joint ventures, e incluso pueden surgir cambios en las motivaciones de cualquiera de ellos. Estas son las ideas de fondo que permiten entender mejor estas ligazones.

Al mismo tiempo, aunque los objetivos estratégicos sean distintos, pueden compartirse los medios tácticos -movimientos indetectables en las fronteras, corrupción a funcionarios, actos de violencia física...- y combinarse de muchos modos para que resulten beneficiosos (Rollins y Wyler 2013: 1-39). La organización del grupo terrorista suele transformarse conforme lo hacen sus necesidades, y es habitual que una organización modifique su agenda política si es conveniente, o que una organización criminal adquiera objetivos políticos (Ibidem).

Las ideas anteriores son necesarias para comprender el fenómeno general de la relación del terrorismo y del narcotráfico porque, de lo contrario, el análisis puede verse limitado por los propios prejuicios y, sobre todo, por la ideología. Los estudios demuestran que el involucramiento en el narcotráfico de grupos terroristas que, a priori, parecería que no deberían hacerlo dados sus principios -religiosos o revolucionarios-, no debe entenderse ni como contradicción ideológica, ni como evolución lógica, sino como parte de una herramienta contingente a la oportunidad, el acceso y la necesidad (Asal, Milward, Schoon 2015: 113). Estas razones explican que en los grupos terroristas con ideología etnopolítica aumente la probabilidad de que se involucren en el narcotráfico (Asal, Milward, Schoon 2015: 120) aunque suela creerse lo contrario.

La ideología no impide, sino frecuentemente refuerza el involucramiento en el narcotráfico. Cuando el tamaño del grupo es grande y, además, controla territorios -antes, las FARC, o hasta hace poco Al Qaeda o Daesh- se facilita que se implique en estas actividades. Este comportamiento suele perjudicar a grupos más pequeños y peor organizados. Es importante insistir en esta idea, porque si se sobrevalorase la idea habitual que sostiene que la carga grande de ideología en un grupo lo aleja del narcotráfico, sería fácil soslayar un hecho cierto: que los grupos terroristas vinculados con redes yihadistas, y los propios grupos yihadistas, se involucran en asuntos de narcotráfico. Al igual que había lazos entre Al Qaeda y la Camorra italiana, puede haberlos entre 
grupos ideológicamente muy lejanos. La ideología puede dar forma a recursos materiales y logísticos, y un grupo puede reinterpretar su ideología para no involucrarse en el crimen organizado, o para implicarse.

En los grupos con fuerte componente religioso la religión no tiene un efecto significativo ni para embarcarse en el narcotráfico, ni para impedirlo. Lo religioso ha sido objeto de estudio amplio en la literatura sobre narcotráfico porque, de un lado, las grandes religiones han sido contrarias a esta actividad -el Vaticano propuso en 2009 excomulgar a los narcotraficantes mexicanos (Wilkinson 2009) y, en los años noventa del siglo XX, el Gobierno de los talibanes en Afganistán prohibió el cultivo de drogas para evitar su consumo entre los musulmanes (Felbab-Brown 2010). Sin embargo, el fortalecimiento del yihad ha legitimado su producción para financiarlo (Ahrari 2009: 43-47), con una salvedad explicitada por ulemas adictos al islamismo: que no se vendan drogas a los musulmanes, pero sí a cualquiera que profese otra religión. La religión ha hecho, a la vez, dos cosas contrarias: ha fortalecido el narcotráfico y lo ha dificultado, por tanto, no puede afirmarse con rotundidad qué efectos priman en la relación de los grupos terroristas con el narcotráfico. Esto indica que es un asunto que debiera estudiarse con más hondura pues es verdad que, dada la naturaleza cambiante del terrorismo -y del nexo cambiante entre terrorismo y delito común- las organizaciones aprenden unas de otras para este tipo de actividades (Makarenko 2004: 129).

La endeblez coercitiva del Estado y el tráfico en drogas se encuentran, a la vez, en áreas tan lejanas como, por ejemplo, Asia Central, Europa Oriental, América Central y el Caribe (Davis 2010: 397-413). Y esa incapacidad coercitiva es una de las claves que permite a los terroristas y a otros delincuentes sumarse a estas aventuras (McDougall 2009: 325). Cuando en un Estado disminuyen las capacidades militares, bien sea por reducciones de personal o de gastos de Defensa, se agrava lo anterior (Albertus y Menaldo 2012: 151-169). Y al revés: cuanto mayor es la capacidad coercitiva del Estado, menor es la probabilidad de que un grupo terrorista se involucre en el narcotráfico. Es habitual la afirmación de que la renta per cápita y la democracia afecta a la actividad terrorista, pero solo la afecta de manera indirecta. Sin embargo, el personal militar per cápita tiene un significativo efecto directo (Asal, Milward, Schoon 2015: 121).

En síntesis, las nuevas alianzas son claras: sus razones son sencillas, pues cualquier causa antisistema es válida para conseguir el objetivo de acabar con los Estados democráticos; los grupos terroristas se apoyan unos a otros cuando les conviene - son tan ideológicos como pragmáticos- y se traicionan si les es ventajoso; se adhieren a causas aparentemente ajenas a sus objetivos prioritarios; y este fenómeno ocurre tanto en la izquierda como en la derecha. 


\section{Islamismo, yihadismo y extrema izquierda}

\subsection{Revolución e islamismo}

Aunque en este artículo se estudia la penetración del islamismo en la extrema izquierda, también ha tenido lugar en la extrema derecha. Desde hace ya algunos años grupos de extrema derecha se han convertido al islamismo. Y algunos conversos han intentado convertir, a su vez, a antiguos combatientes izquierdistas e indigenistas -a miembros del EZLN en Chiapas, por ejemplopara sumar fuerzas (Lara 2002: 79-91; Garvin 2005: 18-19). En estos actos hay un rechazo de la modernidad y de sus implicaciones y los intentos de unificar doctrinas aparentemente contrarias son ejemplos de las "nuevas" y "raras" alianzas que surgen en estos tiempos posrevolucionarios, las cuales no son tan novedosas ni tan raras porque, ya en la Segunda Guerra Mundial, musulmanes radicales combatieron en Europa junto con soldados alemanes con vocación antijudía ${ }^{8}$.

El modo para penetrar en la extrema izquierda es sencillo: acabada la referencia marxista, desaparecidos los triunfos revolucionarios en América, debilitado el clásico internacionalismo, algunos miembros de los grupos clásicos se adhieren a causas nuevas que puedan sustituir a las anteriores. No solo es verosímil -sabido es que ha ocurrido en la extrema derecha-, sino que es posible, y probable, que una de esas causas sea el islamismo. El motivo es que el Islam es una de las fuentes del terrorismo de raíz religiosa, cuyo fortalecimiento comenzó con el triunfo de la revolución islámica de Irán en 1979. A partir de 1992, un año después de desaparecida la URSS, el número de grupos terrorista laicos decayó y aumentó el de los grupos de raíz religiosa (Hoffman 2006: 189-197).

La idea de estas extrañas mezclas es, de nuevo, sencilla: el terrorismo de raíz religiosa sustituye en buena medida a la internacionalidad de las proclamas revolucionarias - hoy, anacrónicas- con la universalidad de las religiones monoteístas (Juergensmeyer 2003). Y de las tres conocidas -cristianismo, judaísmo, islam-es este último el más proclive a la expansión y al proselitismo.

\footnotetext{
${ }^{8}$ Para quienes profesan el nacionalsocialismo, los árabes y el islam son enemigos, pero todos ellos tienen a un enemigo común: los judíos, el sionismo y el Estado de Israel. Hay quienes creen que el islam es la última fuerza tradicional que puede enfrentarse a la conspiración judeomasónica mundial y, aunque sea un argumento falso, es sugerente. Si la violencia es inherente a estas concepciones del hombre y de la historia, el terrorismo -o fórmulas parejas- puede ser tácticamente necesario. Por eso se crean alianzas que van más allá de la conveniencia. La violencia yihadista a la que quieren llegar estos conversos es defensiva. Tiene, incluso, cierto aire de familia a la de las guerrillas de extrema izquierda que abundaron en América, que aspiraban a transformar de raíz a las sociedades y también abominaban de la moderna sociedad de masas. La virulencia del pensamiento islamista y su desprecio de las sociedades abiertas lo hermanan con radicales de toda condición, incluidos los nazis. Se ve en el Daesh que, como contaba Carrión (2015), legitimaba la ejecución de recién nacidos con minusvalías y de menores discapacitados.
}

Araucaria. Revista Iberoamericana de Filosofia, Política, Humanidades y Relaciones Internacionales, año $23, \mathrm{n}^{\circ} 46$. Primer cuatrimestre de 2021. Pp. 215-237. ISSN 1575-6823 e-ISSN 2340-2199 https://dx.doi.org/10.12795/araucaria.2021.i46.11 
Al menos, así permite afirmarlo la experiencia adquirida, visto el número de grupos religiosos, el tipo de atentados y la letalidad de sus actos (Rivas, Rey, Quintana 2017: 93-105). Los atentados del 11 de septiembre de 2001 en los Estados Unidos, los de Madrid de 2004, los de Londres en 2005, los de París en 2015, los de Niza o Bruselas en 2016, los de Estambul en 2018 o los de Malí de 2019, ni siquiera deben explicarse porque son de sobra conocidos.

Al mismo tiempo, cabe recordar que el terrorismo de base cristiana ha afectado esencialmente a los Estados Unidos, pues su intención es redimir a ese país de la influencia que no sea blanca, protestante y anglosajona, además de debilitar el poder federal de Washington y aumentar el de los estados federados, y no pone en aprietos el orden internacional. El terrorismo judío se circunscribe a Oriente Próximo, pues tiene también el deber de redimir la tierra -Palestina- que Dios regaló a Abraham y a su descendencia, tal y como se dice en el Génesis, y expulsar a los árabes de Eretz Israel, sin otras pretensiones ni otros lazos internacionales. Pero los terroristas islámicos, que no son la vanguardia revolucionaria de una clase o de un pueblo -como decían ser los grupos laicos-, se ven a sí mismos como la vanguardia armada que representa a una comunidad religiosa, cuyo fin es acabar con los impíos. Lukacs afirmaba, recordando los deberes del revolucionario, que éste debía aceptar la necesidad de actuar de forma inmoral, pues era el sacrificio más grande que la revolución le demandaba. Era la forma de que el mal se transformara en felicidad a través de la dialéctica de la evolución histórica (en Bell 1981: 547).

Los terroristas laicos que se amparan en el islamismo no aprovechan su vertiente religiosa, sino su fuerza expansiva y revolucionaria -el yihad- que permite combatir al imperialismo. Y el yihadismo combina la motivación política con la legitimación religiosa, la dimensión suicida con la glorificación pública de una violencia justa (Hollander 2013: 527), que se adaptan a las palabras de Lukacs. Cuando Aron (1957: 53) insistía en que el mito de la revolución rompe con el curso cotidiano de los hechos y refuerza la creencia de que todo es posible, solo hablaba de la violencia revolucionaria, con su espontaneidad, modo de vida y autenticidad, pero eso puede ligarse a la violencia yihadista y a su rechazo del mundo moderno. Actualmente, para parte de la izquierda no democrática, la causa de todo mal es el capitalismo, la democracia liberal, la globalización y los Estados Unidos. Y para combatirlos se necesita la violencia. Esa violencia explica cualquier acto de terrorismo (Berman 2010: 151) pues en las equivalencias morales que los antidemócratas construyen, Estados Unidos es el más corrupto sistema político sobre la Tierra y los grupos terroristas se limitan a responder a la política exterior de los EE.UU. Esto sugiere que los lazos de revolución y yihad son mayores de lo que pudiera parecer. Incluso se liga el yihadismo al anarquismo. Un conocido editorial de The Economist del 18 de agosto de 2005 lo hizo en cuatro palabras: "For jihadist, read anarchist". 


\subsection{Guerra revolucionaria y guerra asimétrica.}

Los terroristas laicos no entienden la historia como los yihadistas, ni anhelan construir una teocracia mundial, pero confían en la fuerza revolucionaria de sus proclamas. Si para el terrorista religioso la guerra cósmica en la que participa convierte al enemigo en algo satánico que solo puede destruirse (Juergensmeyer 2003: 254), para el laico esa idea se adapta a lo siguiente: con el enemigo no caben treguas, sino combatirlo hasta la muerte y hasta lograr los objetivos políticos. El título de un interesante artículo de Manfred Sing (2011: 1-44), cuya traducción al español sería "Hermanos de armas: cómo los palestinos maoístas se volvieron yihadistas" es indicativo de este fenómeno. Los maoístas llegaron a la conclusión de que el Islam era un poderoso factor de movilización de masas. Y el concepto de yihad podía superar las debilidades tácticas de los combatientes no estatales -como la OLP ante Israel, por ejemplo-.

El sistema selectivo, acumulativo y contradictorio de creencias diferenciaba a los Hermanos Musulmanes, a Al Fatah y a la izquierda árabe, pero al mismo tiempo los fundía en el antiimperialismo, en la lucha de liberación y en la identidad araboislámica (Sing 2011). Roger Nab'a (2006), antiguo maoísta, llegó a decir que, en Oriente Próximo, el siglo XX solo había tenido cuatro figuras carismáticas: Nasser, Arafat, Jomeini y, uniendo en él a las tres anteriores, el secretario general de Hizbolá, el jeque Nasralá. El islam superaba los modelos revolucionarios de la URSS y de China y revivía la idea de progreso, aunque quisiera reconstruir una revolución semejante a la de Irán. Todas estas razones se asemejan a la idea clásica de guerra revolucionaria, con la salvedad de que sus justificaciones son religiosas.

\subsubsection{Guerra revolucionaria}

Cabe recordar que la guerra revolucionaria estaba marcada por la flexibilidad y la capacidad de adaptación (Rivas y Rodríguez 2010: 31-50). No solo debía hacerse con las armas, sino interviniendo en la vida política (Rivas y Rey 2020) para hacerse con el favor de los votantes y cargarse de legitimidad, o para atraer la atención de los medios de comunicación, extender sus ideas y facilitar la obtención de poder político. También había que extender la lucha del campo a la ciudad. Y si en la revolución no era importante el tiempo, tal y como recordaba Mao en textos clásicos (Mao 1976, 1972, 1963), lo mismo ocurre para los yihadistas. El tiempo de su lucha no se corresponde con el breve de los occidentales, sin cuyas cortapisas mentales y morales se garantizan la victoria futura. Tienen ventaja al trabajar a largo plazo, en períodos que no existen en el imaginario occidental porque se consideran muy lejanos, inalcanzables. No es raro que los yihadistas digan que ellos, o sus hijos, no verán el triunfo, pero que 
quizá sus nietos o bisnietos sí. Y si no fuera así, tampoco importaría, porque acabarán venciendo antes o después (Rivas, 2008).

En la vieja guerra revolucionaria también había que emplear la guerra de guerrillas, y los yihadistas emplean las tácticas de la guerra asimétrica con eficacia. También había que emplear el ejército como instrumento de educación política y de gestión administrativa, y los yihadistas utilizan a sus "ejércitos" para adoctrinar al pueblo y, además, intentan controlar ministerios específicos para gestionar el Estado de forma parcial y modificar el orden político. Los departamentos que más les interesan son los de Asuntos Sociales, del Interior, de Asuntos Religiosos y de Educación (Rivas 2006: 187-188). Con ellos se pueden destinar ayudas generosas a la población y hacerles ver que se debe a la buena voluntad de los islamistas, distinta de la de los corruptos gobernantes que estaban en el poder antes que ellos; se puede dirigir a la policía y a los servicios secretos $\mathrm{y}$, al hacerlo, modificar la política de seguridad y alterar la lucha antiterrorista; es posible nombrar a las autoridades religiosas y controlar lo que se dice en las mezquitas, por ejemplo; o construir el plan de estudios con el que se forma a los estudiantes en la educación primaria y secundaria. Es muy tentador para el yihadista estar en política pues puede modificar el orden desde dentro del régimen. Así que la idea general de flexibilidad y capacidad de adaptación de la guerra revolucionaria se cumple en el nuevo terrorismo de las Américas.

La guerra revolucionaria iba a llevar al mundo al final a un tiempo de paz, y en el caso de los yihadistas, la islamización de la contemporaneidad cumplirá la voluntad de Alá y llevará al mundo al sitio adecuado de la Historia (Rivas 2006: 194); y en el caso de los terroristas laicos, su victoria modificará el orden político instaurando el único orden legítimo -el suyo propio-, que remediará todos los males de los hombres.

La guerra revolucionaria era de aniquilamiento y sin posibilidad de treguas. En los terroristas actuales el criterio es el mismo (Rivas y Patiño 2019: 264-266). Su razonamiento es que, si los enemigos son crueles y los medios empleados son arteros, la única opción legítima para hacerles la "guerra" es el uso de cualesquiera métodos -los asimétricos- para vencer a cualquier precio. $\mathrm{O}$, al menos, para no ser derrotado, lo cual implica que se está venciendo, tal y como decía Begin del Irgun cuando combatía contra el colonizador británico en Palestina: resistir es vencer.

El mando en la guerra revolucionaria debía ser centralizado en lo estratégico y descentralizado en lo táctico (Rivas y Rodríguez 2010: 40-41), y eso es lo que lleva años haciendo Al Qaeda, o el Daesh más recientemente, y enseñándoselo a sus discípulos. Su organización en red y dispersa por todo el mundo, lo favorece (EAI 2018). Es una buena manera de evitar el desmembramiento rápido, aprovechando que sus miembros y sus mandos no 
están en un solo país. Y si a eso se unen los principios anticlausewitzianos que hábilmente emplean los terroristas como evitar la batalla si no hay garantía de victoria, usar medios psicológicos y tiempo para desgastar al enemigo, o evitar los riesgos, se dificulta su persecución y se favorece su engrosamiento.

Añádase que la guerra revolucionaria frecuentemente tenía carácter de liberación nacional, y para los yihadistas actuales, y los insurgentes de izquierda, ese factor sigue vivo. ¿No es acaso la causa del Estado palestino una coartada y una fuente inspiradora, además de un objetivo expresado tanto de yihadistas como de terroristas de izquierda internacionalista? Los yihadistas apelan a la universalidad del Islam y, frecuentemente, a la nación -aunque no aclaren si es umma o watan- lo cual parece una contradicción, pero la liberación nacional y la construcción de naciones es un potente estímulo del terrorismo, quizá porque la nación sigue siendo en el imaginario de nuestro tiempo uno de los lugares esenciales en los que las identidades, individuales o colectivas, nacen, crecen y se desarrollan.

Al mismo tiempo, para complementar lo anterior, cabe sugerir que la mezcla de marxismo e Islam permite la encarnación de la conocida idea de "utopía concreta" de Ernst Bloch, que afirmaba que el marxismo había salvado el núcleo racional de la utopía. Y no se queda en una pura construcción teórica, sino en síntesis verdadera de marxismo tercermundista y de Islam revolucionario (Dot-Pouillard 2008: 17-21).

\subsubsection{Guerra asimétrica}

Hay otro factor para entender la entrada del islamismo en la extrema izquierda, así como estos cambios del terrorismo. Se ha tomado del Islam revolucionario, y es la forma en la que los yihadistas llevan a cabo la guerra asimétrica. Si después del empleo del arma atómica en 1945 -encarnación histórica del "ascenso a los extremos" de Von Clausewitz- hubo un descenso a medios de destrucción más sencillos -como la guerrilla o el terrorismo-, la guerra asimétrica se convierte en la pauta para combatir a cualesquiera Estados (Jones y Johsnton 2013: 1-25). En realidad, los pueblos tribales del mundo árabe la habían empleado antes incluso del nacimiento del Islam en el siglo VII $\mathrm{y}$, aunque la utilizaron también otros, fueron aquéllos los primeros en hacerlo (Garlan 2003; Partner 2002). En el tercer decenio del siglo XXI, el islamismo la emplea como forma de defenderse de las "nuevas cruzadas" (Hollander 2013: 525). Fue en los años 70 cuando la insurgencia islámica empezó a desarrollarse (Hegghammer 2011: 53-94) y cuando la ideología islamista comenzó a extenderse con rapidez.

Todo esto demuestra su superioridad en casi todos los órdenes con respecto a las guerrillas iberoamericanas, algunas de las cuales devinieron 
grupos terroristas y acabaron siendo derrotadas, o disueltas tras acuerdos de paz. Valgan las FARC, clásica referencia guerrillera de las Américas, como ejemplo. La denominada Política de Seguridad Democrática quiso poner a la guerrilla en una situación tan desesperada en el campo de batalla, que acabara aceptando una eventual negociación de paz en la que las líneas maestras las pusiera el Estado. Las FARC no estaban debilitadas del todo y el predominio de la acción militar sobre la ideología fue uno de los factores que permitieron que la organización perviviera (Peco y Peral 2006: 39). Por eso Pecáut (2003: 190) decía que las FARC no querían reeditar la toma del Palacio de Invierno de San Petersburgo, es decir, sabían que necesitaban la vía política y por eso querían crear una situación nacional catastrófica para que, al final, el Gobierno tuviera que negociar con ellas a cualquier precio. $\mathrm{Y}$ así ha sido, visto el resultado de las negociaciones de La Habana. Pese a ellas, y de haberse considerado a las FARC desde los años 60 como parte de la intención revolucionaria ligada a la URSS y a Cuba, había indicios desde hacía años de lazos entre este grupo y células locales de Al Qaeda e incluso de Hizbolá (Murillo 2004: 58-59). Con estos datos se adivinan ciertas conexiones interregionales (EAI 2018).

No quiere esto decir que las FARC se islamizaran, o que estuvieran tentadas de hacerlo, sino que el más longevo grupo de las Américas, que tuvo la posibilidad de tomar el poder en Colombia, acabó siendo derrotado. Y que eso muestra lo siguiente: es verosímil pensar que estos grupos de América Latina se han interesado por la eficacia de la guerra asimétrica y la aprenden de los más hábiles en llevarla a cabo, que la han experimentado exitosamente en Afganistán, Irak, Somalia, Nigeria o Siria. Tanto ha sido así que Daesh ha llegado a tener control territorial de un territorio en Siria y en Irak con espacio similar al de Jordania, ha logrado modificar las fronteras de Oriente Medio y ha perfilado un califato territorialmente discontinuo con wilayas que le juraban lealtad en el Magreb y en el Mashrek, con leyes propias, moneda y comercio. Por eso, este motivo pragmático es una de las razones de las nuevas alianzas, cuyas legitimaciones de la violencia se hacen paso a paso e incluyen argumentos religiosos y culturales. Al internacionalismo le acompaña el particularismo; al criticismo, las creencias religiosas; y a la necesidad histórica, la voluntad de Dios (Sing 2011: 44).

\subsection{Síntesis doctrinal, yihad y terrorismo suicida}

A estas ideas puede unírsele un concepto de Ilich Ramírez Sánchez, más conocido por El Chacal. Este terrorista venezolano -preso en París- afirmaba que el Islam le daba al marxismo la espiritualidad e idealismo que él no tenía, y el marxismo le daba al Islam la capacidad analítica de la que carecía (Ramírez 2003). Esta idea, que fortalece la teoría y la práctica revolucionaria, 
es un objetivo en parte de los grupos terroristas actuales. Se aspira a hacer el yihad - contra el imperialismo, el Estado, lo que sea-, se sea musulmán o no, se aspire a lograr teocracias islámicas o un mundo diferente, porque el yihad es la continuación lógica de la revolución.

Para Bloch la utopía posible generaba esperanza y movía a los individuos a luchar por conseguirla, y su utopía concreta se situaba al final de los tiempos, cuando llegara el hombre pleno. Bloch fue el "profeta apocalíptico de la nueva religión de la utopía" (Gálvez 2008: 60). Con una teoría islamizada de la revolución, las masas pueden triunfar al margen de las circunstancias si permanecen unidas y, aunque el enemigo pueda parecer más fuerte, la Historia demostrará que los guerreros de Dios vencerán debido a sus creencias y a su unidad (Rivas y Rey 2018: 92-105). Es, finalmente, una práctica islamizada de la revolución, una profecía de la victoria final que puede soslayar cuestiones concretas -el momento adecuado, los medios necesarios o los resultados inmediatos-que era, precisamente, lo que debilitaba al marxismo. Los actos del yihadismo son inmunes a la crítica o al fracaso. Ni siquiera necesitan tenerlos en cuenta como posibilidad, porque dependen de la Providencia divina.

Esto se liga con el hecho de que el yihad es una obligación jurídica y religiosa $-\mathrm{y}$ en esto último insisten los islamistas, pues está prescrita por Dios y su Profeta- y persiste hasta el día de la Resurrección mientras el Islam no se haya extendido por toda la Tierra. El yihad en el Islam significa tanto "guerra santa" como "esfuerzo personal" del creyente por mejorarse, tal y como decía Mahoma y aparece en el Corán, pero las interpretaciones viciadas y las necesidades de los islamistas la han transformado. Abd Alá Azzam, de origen palestino-jordano, cofundador de Hamás, uno de los padres del internacionalismo islamista, elaboró un cuerpo doctrinal en los años ochenta para hacer el yihad a escala mundial que permitió captar gentes en todo el mundo islámico. Llegó a predicarlo contra Occidente y los judíos incluso en los Estados Unidos entre 1985 y 1989.

Ahora son los salafistas, que dicen haber logrado recuperar las esencias del Islam -se definen a sí mismos como "originales", gayr muqalidun- quienes más han deformado el concepto de yihad para justificar la barbarie terrorista. Para ellos el creyente que lo ejerce, entendido como guerra contra el infiel, es el mejor de los hombres. Y para ello invocan las aleyas belicistas de la etapa de Medina -las del "primer Islam"-, en las que Mahoma era un "profeta en armas". En las azoras de Medina el Corán legitima la guerra contra los infieles y la convierte en deber sagrado. La única fórmula para el islamista - que no sea mesurado, suponiendo que la moderación sea posible en esta doctrina- es la violencia. La consecuencia es una ideología combativa centrada en la necesidad de hacer el yihad tanto contra Occidente como contra los musulmanes que se oponen a la visión que el islamismo tiene del Islam. El terrorismo es un acto de 
legítima defensa. Abbas Musawi, fundador de Amal Islámica y, después, uno de los jefes de Hizbolá, decía ya en 1983 que cada musulmán a quien Israel, o América, o Francia o cualquiera otra fuerza maligna hubiera dañado, tenía el deber de combatir el mal con el mal (en Fisk 2011: 521). Es una especie de guerra total contra la guerra total en la que hay virtud. Mientras más trágica sea la Historia de los hombres - cree el islamismo- más cerca estará el Reino de Dios.

De este vigor sagrado refuerza la izquierda insurgente su lógica revolucionaria. Mientras más duro se sea en el combate contra el enemigo, más cerca estará el Reino Revolucionario. Aunque no se lograra atraer masas ingentes a esta lucha, la promesa de la segura victoria final -incluso retrasada en el tiempo- seguiría siendo ejemplar para la construcción del discurso intransigente y militante (Kahati 2019). La lucha armada, la pura violencia, es una prioridad tal que se vuelve un artículo de fe (Sing 2011: 7).

La manifestación de todo esto es el terrorista suicida, pues sustituye un enfrentamiento prolongado más difícil, es rentable para la causa terrorista y reduce el número de víctimas propias. Es un arma barata, manejable, precisa (Bloom 2005), cuyas ventajas han comprendido bien los terroristas (Pape 2005: 22). En realidad, el terrorismo de carácter religioso invoca siempre su carácter defensivo. Ejerce una violencia redentora, que pone en orden un mundo desordenado e injusto para con la causa que defiende el terrorista y, en el caso del suicida, su destino personal se desvanece al volverse un catalizador para la victoria, que no necesita vivir para ver la victoria final (Sing 2011: 44). Así que la guerra asimétrica - con estas pinceladas de yihad-ahorra vidas y da ventaja al terrorista: no vence por las armas a un Estado, pero no es derrotado. Y además se carga de legitimidad cuando quienes la ejecutan no están en condiciones de enfrentarse al enemigo con reglas, que es lo que el enemigo quiere.

Esta guerra asimétrica está a la orden del día y se fortalecerá en el futuro (Jones y Johnston 2013: 8 y 19) por mucho que los Estados tengan capacidades mayores que los actores no estatales. Y el aumento de ocupaciones militares de un territorio contribuye al aumento de la guerra asimétrica, con lo que ello conlleva. Por eso el razonamiento terrorista -similar al de los viejos terroristas del Irgun, que atacaron a los británicos en el protectorado de Palestina- se resume en "quien resiste, vence", porque sabe que no se puede batir al enemigo -si es un Estado- en el campo de batalla.

\section{Conclusiones}

Creemos que en este trabajo se ha logrado demostrar la veracidad de las dos hipótesis: que el islamismo ha calado en las ideologías extremistas 
de izquierda vistas las conexiones crecientes entre grupos clásicamente latinoamericanos y otros de raíz islamista, y que la conjunción de islamismo y extrema izquierda permite construir una suerte de teoría y práctica islamizada de la revolución. Las conclusiones principales son las siguientes:

1. Los grupos terroristas de América tienen relaciones con los de otras zonas del mundo, mezclan ideologías a su conveniencia, se vinculan con el delito común y, cada vez con más frecuencia, lo religioso es capital. En todo ello el narcotráfico es un factor clave.

2. Debilitados el pensamiento marxista, el internacionalismo y la teoría y la práctica revolucionaria, una parte de la extrema izquierda se adhiere a causas nuevas. Una causa nueva a la que se suma es el terrorismo de base religiosa, porque las religiones monoteístas pueden sustituir a la internacionalidad de las consignas revolucionarias. El islam es esa religión, por ser más proselitista, y porque su versión fundamentalista, el islamismo, ha demostrado una mayor letalidad en parte de los atentados recientes más reconocidos -Madrid, París, Bruselas-, además de que la mayoría de los grupos terroristas eficaces en activo son islámicos.

3. Una de las acepciones del concepto de yihad se puede adaptar con naturalidad a la lógica revolucionaria clásica, y de su potencia expansiva puede beber una nueva revolución. Por ello, tanto la lógica como la práctica del yihadismo se asemejan a la teoría y la práctica de la guerra revolucionaria en hechos concretos: debe combatirse con las armas y en la vida política; debe trabajarse sin tiempo, a largo plazo, como en la guerra prolongada de Mao; llevará a la Historia a un tiempo de paz tras implantar el régimen político idóneo para ello; la posibilidad de tregua es residual porque la lógica imperante es la del aniquilamiento del enemigo; el mando debe ser centralizado en lo estratégico y descentralizado en lo táctico; y debe tener carácter de liberación nacional, en un sentido extenso de la palabra.

4. De esto se desprende que marxismo e islam fundidos encarnan una utopía concreta. A la espiritualidad de uno puede sumársele el método del otro, en síntesis doctrinal muy útil para fortalecer el terrorismo actual. Una teoría islamizada de la revolución permite que pueda hacerse el yihad -obligación jurídica y religiosa- contra quien sea o contra lo que sea, porque es continuación lógica de la revolución, fabricando una práctica islamizada de la revolución. De ahí que el sector más extremista de la extrema izquierda puede empaparse de esta doctrina.

5. Los yihadistas hacen la guerra asimétrica contra sus enemigos, pues la cultivan desde tiempo atrás, con éxito, en diversos lugares del mundo, ya sea en los grupos armados de las wilayas leales al Daesh en 
la costa libia, las facciones de Boko Haram en Nigeria, o los triunfos de los muyahidín en Afganistán. Esa guerra asimétrica es superior a la que hicieron en América las guerrillas, algunas de las cuales tiempo después se convirtieron en grupos terroristas, percibieron las ventajas de los métodos de los islamistas y se dieron cuenta de que ejercerla acaso podría ayudarles a lograr sus objetivos.

6. La manifestación más clara y eficaz de todo esto es el terrorismo suicida, inscrito en un terrorismo entendido como acto de legítima defensa, es decir, como una fuerza que deja de ser inicua porque no es violencia -vis injusta-, sino fuerza justa. Es barato, rápido y quien lo lleva a cabo se vuelve artífice -anónimo pero esencial- de la victoria final, además de acreedor de la solidaridad de aquellos a quienes dice defender. La guerra asimétrica es un concepto bélico en el que encaja bien y, probablemente, seguirá siendo la pauta, incluso fortalecida, en los próximos años.

En un trabajo más extenso, que excede a las posibilidades de un artículo, podría ampliarse este estudio. Sugerimos dos ideas: analizar las modificaciones de naturaleza de la izquierda y de la derecha extremas tras la penetración islámico-yihadista en ellas para estudiar cómo cambia su discurso público y su comportamiento; y sistematizar pormenorizadamente los cambios del terrorismo en Latinoamérica para, en un ejercicio de prospectiva, sugerir algunas contramedidas eficaces, como colaboración de la Academia con los organismos públicos que se enfrentan a estas organizaciones. 


\section{Referencias bibliográficas:}

Ahrari, Ehsan,"The Dynamics of "Narco-Jihad" in the Afghanistan-Pakistan Region" en The National Bureau of Asian Research Special Report, 20 (2009), pp. 43-47

Albertus, Michael y Menaldo, Victor, "Coercitive Capacity and the Prospects for Democratization" en Comparative Politics, 44 (2012), pp. 151-169.

Aron, Raymond, The Opium of Intellectuals, London, Secker \& Warburg, 1957. Asal, Victor; Milward, Brinton y Schoon, Eric, "When Terrorists Go Bad: Analyzing Terrorists Organizations' Involvement in Drug Smuggling" en International Studies Quarterly, 59 (2015), pp. 112-123.

Avilés, Juan, "Terrorismo anarquista y terrorismo yihadí: un análisis comparativo" en Historia y política, 27 (2012), pp. 227-249.

Badran, Tony, "Levant in Focus: Hizbollah Acts Local, Thinks Global" en Jerusalem Post, 23 de junio de 2010.

Bar, Shmuel, "Deterring Non-State Terrorist Groups: The Case of Hizballah" en Comparative Strategy, 26 (2007), pp. 477-478.

Bell, Daniel, "First Love and Early Sorrows" en Partisan Review, 48 (4) (1981), pp. 532-551.

Berman, Paul, The Flight of the Intellectuals, New York, Melville House, 2010. Bloom, Mia, Dying to Kill, New York, Columbia University Press, 2005.

Byman, Daniel et al, Trends in Outside Support for Insurgent Movements, Santa Monica, Rand Corporation, 2001.

Caro, Isaac, "Presencia de movimientos chiitas en América Latina" en Latin American Research Review, 46 (1) (2011), pp. 177-193.

Caro, Isaac, Islam y judaísmo contemporáneo en América Latina, Santiago de Chile, RIL editores, 2010.

Caro, Isaac, "Fundamentalismos islámicos y judeofobia: conexiones sudamericanas" en Cuadernos Judaicos 26 (2009), pp. 1-9.

Carrión, Francisco, "El Estado Islámico ordena asesinar a los recién nacidos con discapacidad" en El Mundo, 14 de diciembre de 2015.

Centeno, Miguel Ángel, Sangre y deuda, Bogotá, UNAL, 2014.

Chanona, Alejandro, "Regional Security Governance in the Americas" [en Kirchner, Emil y Domínguez, Roberto, coords.: The Security Governance of Regional Organizations, Oxon, Routledge, 2011], pp. 107-135.

Chepesiuk, Ron, "Dangerous Alliance: Terrorism and Organized Crime" en Global Politician, 11 (2007). Disponible en: http://www.globalpolitician. com/23435-crime

Clutterbuck, Richard, Guerrilleros y terroristas, México, FCE, 2004. 
Davis, Diane, "Irregular Armed Forces, Shifting Patterns of Commitment and Fragmented Sovereignity in the Developing World" en Theory and Society, 39 (2010), pp. 397-413.

Domínguez, Florencio, Las conexiones de ETA en América, Madrid, Debate, 2010.

Dot-Pouillard, Nicolas, "De Pekin a Teheran, en regardant vers Jerusalem: la singuliere conversion a l'islamisme des «《Maos du Fatah》" en Cahiers de l'Institut Religioscope 2 (2008), pp. 1-39.

EAI, Entrevista con agentes de inteligencia (Latinoamérica, Israel, España), 2018.

Felbab-Brown, Vanda, Shooting Up: Counterinsurgency and the War on Drugs, Washington DC, Brookings Inst. Press, 2010.

Fisk, Robert, Pity the Nation. Lebanon at War, Oxford, Oxford University Press, 2001.

Gálvez, Isidro, "La función utópica en Ernst Bloch" en II Coloquio de Doctorandos, UNAM, 2008. Disponible en: http://www.posgrado.unam. mx/filosofia/wp-content/uploads/2018/09/04galv.pdf

Garlan, Yvonne, La Guerra en la Antigüedad, Madrid, Aldebarán, 2006.

Garvin, Natascha, «Conversion \& Conflict Muslims in Mexico » en ISIM Review, 15 (2005), pp. 18-19.

Hegghammer, Thomas, "The Rise of Muslim Foreign Fighters" en International Security, 35 (3) (2011), pp. 53-94.

Hoffman, Bruce, Inside Terrorism, New York, Columbia University Press, 2006.

Hollander, Paul, "Righteous Political Violence and Contemporary Western Intellectuals" en Terrorism and Political Violence, 25 (4) (2013), pp. 518530.

Ignatieff, Michael, El honor del guerrero, Madrid, Taurus, 1999.

Jones, Seth y Johnston, Patrick, "The Future of Insurgency" en Studies in Conflict and Terrorism, 36 (1) (2013), pp. 1-25.

Juergensmeyer, Mark, El terrorismo religioso, Madrid, Siglo XXI, 2003.

Kahati, Yoram, reunión informativa con el subdirector del Meir Amit Intelligence and Terrorism Information Center, Tel Aviv, julio de 2019.

Kaldor, Mary, Las nuevas guerras. Barcelona, Tusquets, 2003.

Karmon, Ely, "Iran and Its Proxy Hezbollah" en Working Paper RIE 18 (2009), pp. 1-32.

Karmon, Ely, "Hezbollah's Global Reach" en Hearing of the House Committee on International Relations, September, 2006.

Laqueur, Walter, The Age of Terrorism, Boston, Little Brown, 1987. 
Lara, Marco, « ¿El Islam en Chiapas?: el EZLN y el Movimiento Mundial Murabitun » en Revista Académica para el Estudio de las Religiones, 4 (2002), pp. 79-91.

Makarenko, Tamara, "The Crime-Terror Continuum; Tracing the Interplay between Transnational Organised Crime and Terrorism" en Global Crime, 6 (2004), pp. 129-145.

Manheim, Jarol y Rich, Richard, Empirical political analysis. Research methods in political science, New York, Longham, 1986.

Mao Tse Tung, La guerra de guerrillas, Buenos Aires, Editorial Huemul, 1963.

Mao Tse Tung, Seis escritos militares del presidente Mao Tse Tung, Pekín, Ediciones en Lenguas Extranjeras, 1972

Mao Tse Tung, La guerra prolongada, Barcelona, R. Torres, 1976

McDougall, Alex, "State Power and its Implications for Civil War in Colombia" en Studies in Conflict and Terrorism, 32 (2009), pp. 322-345.

McMullin, Jaremey, "Organised Crime Groups and Conflict: The Nature and Consequences of Interdependence" en Civil Wars, 11 (2009), pp. 75-102.

Merlos, Alfonso, La infiltración islamista y la amenaza yihadista en América Latina, Madrid, FIE, 2009.

Merton, Robert; Fiske, Marjorie; Patricia Kendall, The focused interview: a manual of problems and procedures, Glencoe, Free Press, 1946.

Moghadam, Assaf, "How Al Qaeda Innovates" en Security Studies 22 (3) (2013), pp. 466-497

Murillo, Mario, Colombia and the United States. War, Unrestand Destabilization, NY, Seven Stories Press, 2004.

Mussawi, Ammar, entrevista en Beirut, julio de 2017.

Nab'a, Roger, "Wali-mādhā al-rumūz fĩ zaman al-miḥan" en $A l-A k h b \bar{a} r, 6$ de septiembre de 2006. Disponible en http://www.al-akhbar.com/arl node/3715

Nasr, Vali, The Shia Revival, New York, W.W. Norton \& Company, 2006.

Pape, Robert, Dying to Win: The Strategic Logic of Suicide Terrorism, New York, Random House, 2005.

Partner, Peter, El dios de las batallas, Madrid, Oberon, 2002.

Pécaut, Daniel, Midiendo fuerzas, Bogotá, Editorial Planeta, 2003

Peco, Miguel y Peral, Luis, El conflicto de Colombia, Madrid, Ministerio de Defensa, 2006

Post, Jerrold; Mcginis, Cody; Mody, Kristen, "The Changing Face of Terrorism in the $21^{\text {st }}$ Century" en Behavioral Sciences \& the Law, Buffalo, 32 (3) (2014), pp. 306-334.

Rainier, Gabino, reunión en 2017 con agentes de inteligencia de tres países latinoamericanos - cuyos nombres están unificados en el nombre modificado de Gabino Rainier-. 
Ramírez, Ïlich, L'Islam révolutionnaire, Monaco, Editions du Rocher, 2003.

Rapoport, David, "Terrorism" [en Hawkesworth, Mary y Kogan, Maurice, eds.: Routledge Encyclopedia of Government and Politics, London, Routledge, 2011], pp. 1061-1082.

Reinares, Fernando, "España frente a los retos de un yihadismo en cambio" en ARI, 6 (2015), pp. 1-6.

Reinares, Fernando, Terrorismo y antiterrorismo, Barcelona, Paidós, 1998.

Rivas, Pedro y Patiño, Milena, "De la extensión del mal mediante la violencia terrorista: discurso del odio, publicidad con sangre y propaganda por el hecho" [en Blanca Martín, coord..: La prevención y represión del discurso del odio. Hacia la construcción multidisciplinar de la tolerancia, Pamplona, Thomson Reuters Aranzadi, 2019], pp. 241-272.

Rivas, Pedro y Rey, Pablo, "Enseñanzas de la guerra revolucionaria y de la respuesta contrarrevolucionaria para la lucha antiterrorista" [en Molina, Miguel y González, Rafael, eds.: Seguridad y defensa. Estrategias y desafios en un mundo globalizado, Granada, UGR-MADOC, 2020], pp. 59-78.

Rivas, Pedro y Rey, Pablo, “El martirio: génesis de un arma contemporánea” [en Domínguez, José, coord.: Problemas emergentes de seguridad. Riesgos y amenazas presentes y futuras, Sevilla, CISDE, 2018], pp. 92-105.

Rivas, Pedro; Rey, Pablo; Quintana, Nuria, "El discurso público del yihad y las modificaciones de la violencia política en Latinoamérica" [en Bermúdez, Manuel y Macho, Rafael, eds.: Análisis del discurso mediático: un enfoque multidisciplinar, Sevilla, Editorial Egregius, 2017], pp. 93-105.

Rivas, Pedro y Rodríguez, María, "La política de las armas", Revista Enfoques, 8 (13 (2010), pp. 31-50.

Rivas, Pedro, Entrevista a un mando de Hamas, Ras al Amud, Jerusalén, julio de 2008.

Rivas, Pedro, "Islam e islamismo, o el problema de la convivencia. Barbarie intraconfesional y yihadismo contemporáneo" [en Miguel Ángel Quintana, ed.: Europa, siglo XXI: secularización y Estados laicos, Madrid, Ministerio de Justicia, 2006], pp. 176-195.

Rollins, John y Wyler, Liana, "Terrorism and Transnational Crime: Foreign Policy Issues for Congress" en Congressional Research Service, 19 (2013), pp. 1-39.

Rudner, Martin, "Hizbullah Terrorism Finance: Fund-Raising and MoneyLaundering" en Studies in Conflict and Terrorism, 33 (8) (2010), pp. 705 716.

Schmidt, Alex, Political Terrorism: A Research Guide, New Jersey, Transaction Books, 1984. 
Schoen, Douglas y Rowan, Michael, The Threat Closer to Home, New York, Simon \& Schuster, 2009.

Shelley, Louise y Picarelli, John, "Methods Not Motives: Implications of the Convergence of International Organised Crime and Terrorism" en Police Practice and Research: An International Journal, 3 (4) (2002), pp. $305-$ 318.

Sing, Manfred, "Brothers in Arms: How Palestinian Maoists Transformed Jihadists" en Die Welt des Islams, 51 (1) (2011), pp. 1-44.

Teirilä, Olli, "The Challenges to Cooperation Posed by the Nexus of Terrorism and Organized Crime: Comparing the Situations Between the Andean and the Sahel Regions" en Studies in Conflict and Terrorism, 37 (1) (2014), pp. 18-40.

Upal, Afzal, "Confronting Islamist Jihadist Movements" en Journal of Terrorism Research, 6 (2) (2015), pp. 57-69.

Vargas, Gonzalo, "Drugs, Hearts and Minds: Irregular War and the Coca Economy in south Bolivar, Colombia (1996-2004)" en Civil Wars, 12 (2011), pp. 21-39.

Wamg, Peng, "The Crime-Terror Nexus: Transformation, Alliance, Convergence" en Asian Social Science, 6 (6) (2010), pp. 11-20.

Wardlaw, Grant, Terrorismo político, Madrid, Estado Mayor del Ejército, 1986.

Weinberg, Leonard y Eubank, William, "An End to the Fourth Wave of Terrorism?" en Studies in Conflict and Terrorism 33 (7) (2010), pp. 594602.

Wiewiorka, Michel, Societés et Terrorisme, Paris, Fayard, 1988.

Wilkinson, Tracy, "Vatican Suggests Excommunicating Mexican Drug Traffickers" en Los Angeles Times, 13 de enero de 2009. Disponible en: http://www.latimes.com/world/la-fg-vatican-mexico13-2009jan13-story. $\underline{\mathrm{html}}$

Wilkinson, Paul, Terrorism and the Liberal State, London, MacMillan, 1986. 
